\title{
Mucormicosis pulmonar
}

PAMELA SILVA G. y CARMEN L. AVILÉS L.

\section{Pulmonary mucormycosis}

A case of a 10 year old boy with acute lymphoblastic leukemia, and neutropenia secondary to chemotherapy, is presented. He received multiple antibiotics for a pulmonary abscess before surgical drainage. A mucormycosis was diagnosed by histopathology of the lung, after which he received successfully amphotericin deoxicolate treatment. An early clinical suspicion of fungal infection in children with risk factors, specially diabetes and immunocompromise, and an opportune treatment is fundamental in decreasing mortality in this opportunistic disease.

Key words: mucormycosis, pulmonary disease.

\section{Introducción}

Mucormicosis o zygomicosis es una infección aguda oportunista, causada por hongos de la clase Zygomycetes de la familia Mucorales. Dentro de esta familia los géneros más frecuentemente aislados son Rhizopus, Mucor y Absidia. Estos organismos viven en el ambiente y penetran en el organismo por inhalación de esporas a través de la vía aérea; a través de piel por heridas contusas abiertas, catéteres, líneas venosas); o por vía gastrointestinal. Su cuadro clínico más frecuente corresponde al compromiso rinocerebral y en segundo lugar el compromiso pulmonar.

El aumento de pacientes que reciben terapias inmunosupresora y pacientes cancedrosos son sometidos a quimioterapia más agresiva, ha permitido que esta afección se manifieste con mayor frecuencia ${ }^{1}$. El pronto reconocimiento y tratamiento de ella conlleva un mejor pronóstico.

Se presenta el caso clínico de un niño con leucemia y neutropenia, con diagnóstico histopatológico de mucor pulmonar tratado exitosamente con un enfoque médico-quirúrgico agresivo.

\section{Caso Clínico}

Paciente de sexo masculino quien a los 10 años de edad se le diagnosticó una leucemia linfoblástica aguda T, tipo L2, CALLA (-), con hiperdiploidia y factor de riesgo 1,0. Inició tratamiento en diciembre de 1995, consiguiéndose remisión completa.

En junio de 1996 recibía fase II del protocolo nacional de tratamiento (PINDA) en su tercera semana (dexametasona, vincristina, adriamicina, asparraginasa), cuando presentó un cuadro de omalgia izquierda y dolor en el hemitórax ipsilateral, con tope inspiratorio. En el examen físico de ingreso se le describió como: paciente quejumbroso, polipneico, afebril, con vesículas en la piel, de distribución generalizada. En el examen pulmonar se encontró disminuido el murmullo vesicular en la base del hemitórax izquierdo. La radiografía de tórax (RxT) mostró una imagen de consolidación en base y tercio medio del pulmón izquierdo, con broncograma aéreo. Entre sus exámenes destacaban: hemograma con hemoglobina $12,5 \mathrm{~g} / \mathrm{dl}$, leucocitos $600 / \mathrm{mm}^{3}$, con recuento absoluto de neutrófilos de $0 / \mathrm{mm}^{3}$, plaquetas 70.000/mm 3 , VHS: 130 mm/h, PCR: 264,7mg/L.

Se hizo el diagnóstico de varicela y neumonía con focos múltiples iniciándose terapia con aciclovir endovenoso y penicilina sódica que recibió durante $24 \mathrm{hrs}$. Al recibirse informe de hemocultivos positivos a Streptococcus pneumoniae con CIM intermedia para penicilina se cambió a cefotaxima

Evolucionó afebril y se recuperó de la aplasia en forma completa ya al $7^{\circ}$ día, persistiendo la PCR (134,5 mg/L). Al $8^{\circ}$ día reapareció la fiebre, 
en forma intermitente con alzas aisladas, manteniendo buen estado general. El día $13^{\circ}$ de evolución se controlo PCR que resultó de $272 \mathrm{mg} / \mathrm{L}$, y la RxT (Figura 1) mostró consolidación basal izquierda, aparición de un nivel líquido en esa zona y desviación del mediastino hacia el lado derecho. Se realizó una ecografía torácica que demostró un gran absceso pulmonar en el lóbulo inferior izquierdo con nivel líquido. Se modificó entonces la antibioterapia agregándose clindamicina y amikacina. Al día siguiente se repitió la RxT encontrándose cardiomegalia, por lo que se solicitó un ecocardiograma que mostró derrame pericárdico anterior de $16 \mathrm{~mm}$ y posterior de $18 \mathrm{~mm}$.

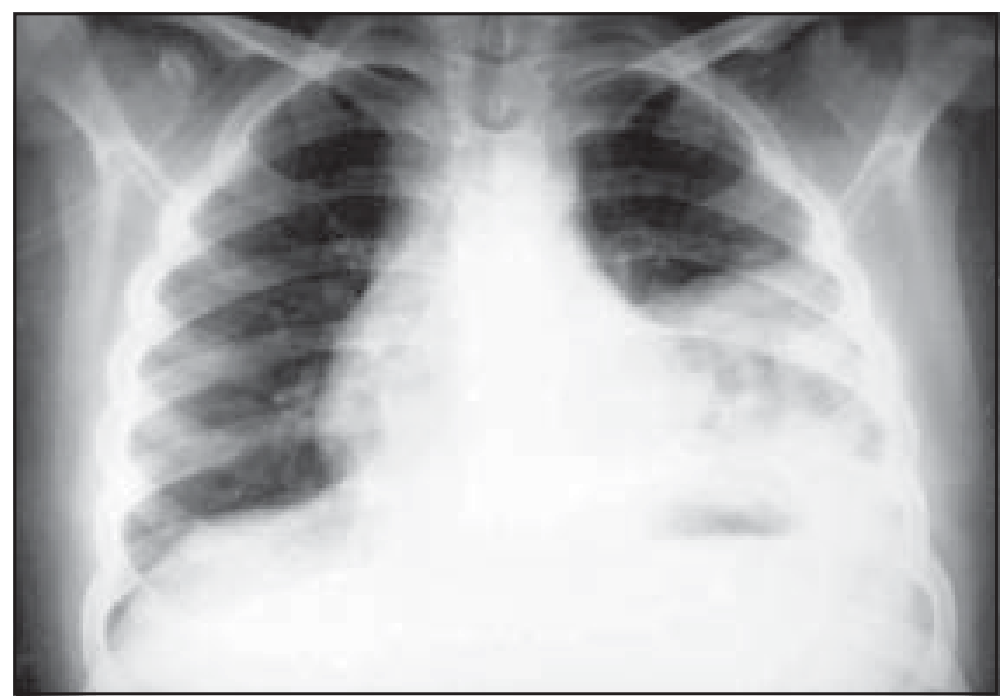

Figura 1. Rx de tórax. Día 13. Consolidación de la base izquierda con nivel líquido y desviación del mediastino hacia el lado derecho.

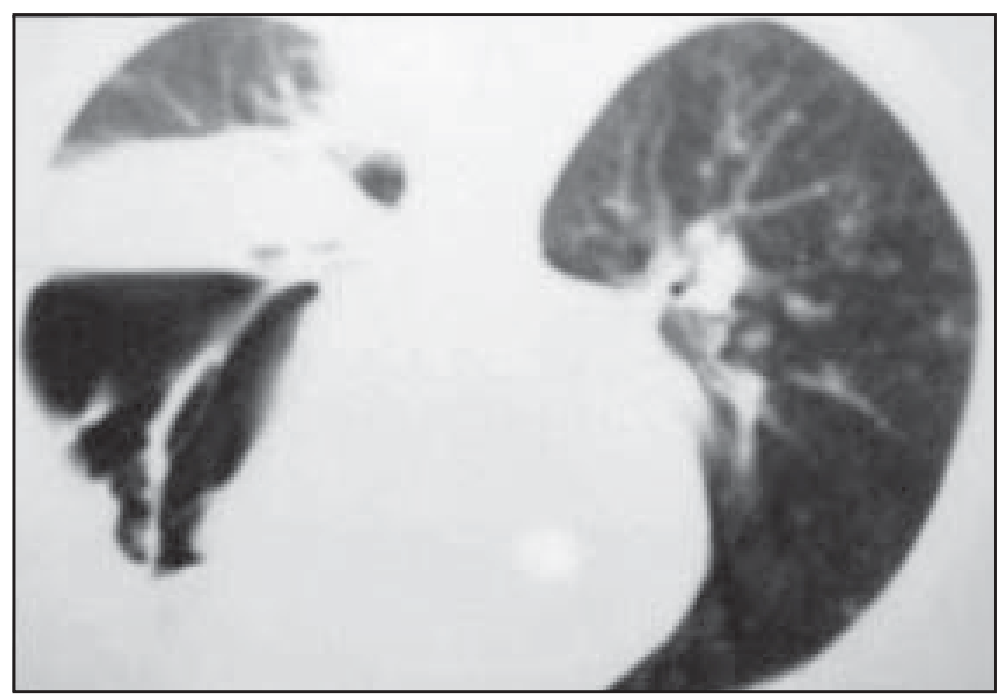

Figura 2. TAC de tórax. Día 15. Imagen de absceso pulmonar izquierdo de 10 $\mathrm{cm}$. de diámetro, con nivel hidroaéreo.
Una TAC de tórax (Figura 2) mostró imagen de absceso pulmonar izquierdo, de $10 \mathrm{~cm}$ de diámetro mayor, tributario de la língula, con loculaciones y nivel hidroaéreo.

El día 21 desde su ingreso se drenó quirúrgicamente un absceso que medía 20 por $15 \mathrm{~cm}$, adherente a pericardio y constituido por material grisáceo, ligoso. Se realizó cistodebridamiento, resección pulmonar parcial y aseo del espacio pericárdico, donde se encontraba escasa cantidad de líquido. Se envió material a estudio bacteriológico e histológico identificándose Staphylococcus aureus y Klebsiella sp del cultivo bacteriológico; y en el informe histopatológico se describió: "parénquima pulmonar con extensas áreas de necrosis de coagulación y presencia de hifas de tamaño variable no septadas, ramificadas en ángulo recto, ubicadas en forma difusa; otras áreas con infiltrado inflamatorio polimorfonuclear formando abscesos con necrosis" (Figura 3). Se interpretó como una mucormicosis pulmonar con infartos y formación de abscesos. Los cultivos para hongos del aspirado bronquial, herida operatoria y nasal fueron negativos.

Recibió tratamiento con anfotericina B deoxicolato completando $35 \mathrm{mg} / \mathrm{kg}$ (51 días), cefotaxima ( $21 \mathrm{ds})$, amikacina (8 ds), gentamicina (10 ds), sulperazona $(27 \mathrm{ds})$ y clindamicina (37ds).

Evolucionó estable pero con alzas febriles intermitentes hasta 27 días después de iniciada la anfotericina B, la PCR se normalizó a los 33 días de tratamiento.

Reanudó la quimioterapia luego de tres meses, completando tratamiento en diciembre de 1997. Hasta la fecha actual (5 y $1 / 2$ años de seguimiento) se mantiene en remisión de la leucemia, en buenas condiciones generales, asiste a la escuela, sin limitación en sus actividades diarias. Fue dado de alta en la Unidad de Broncopulmonar. 


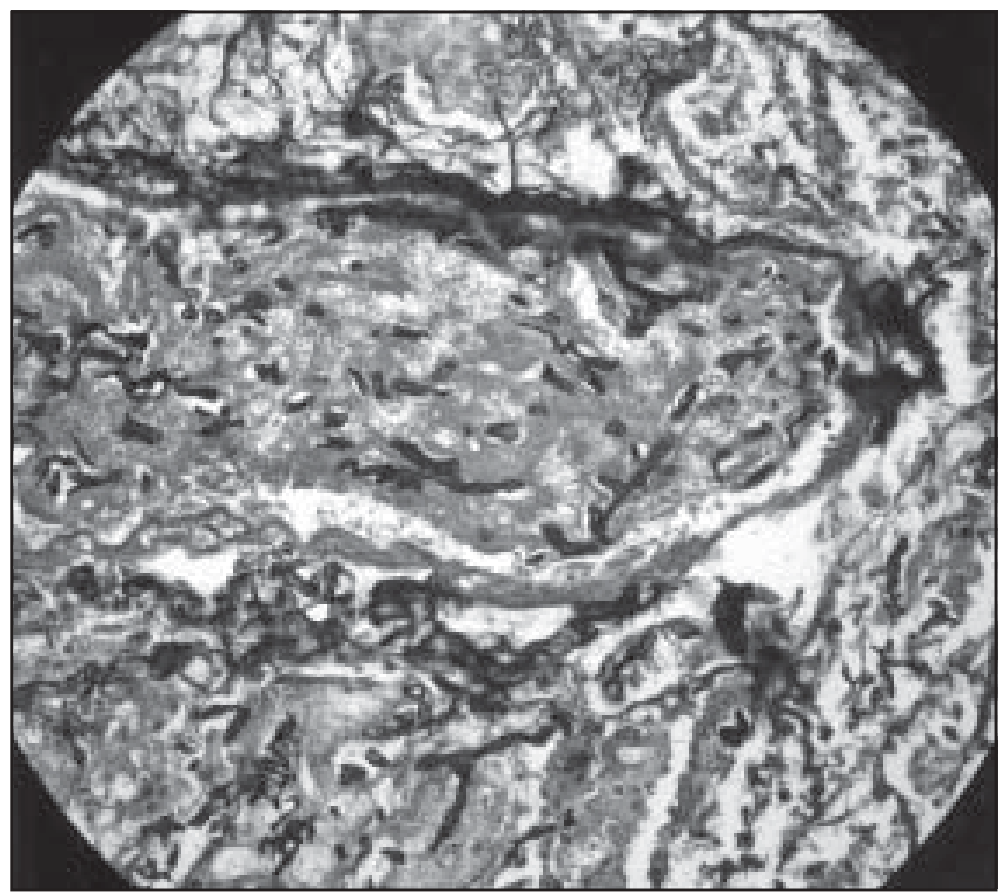

Figura 3. Histopatología pulmonar

\section{Discusión}

En este caso clínico destacó la persistencia de fiebre y PCR elevada, explicables por la presencia de un absceso pulmonar en un paciente con varios factores predisponentes: leucemia, aplasia medular con neutropenia severa por quimioterapia, e infección bacteriana mixta. El examen histopatológico del material obtenido durante el acto operatorio de resección del absceso pulmonar mostró la presencia de hifas con características típicas de zigomicosis, y que por sus ramificaciones en ángulo recto y la ausencia de septos, más la presencia de infarto y necrosis tisular, permitieron efectuar el diagnóstico de mucormicosis. En los casos descritos en la literatura médica se describe con frecuencia la dificultad para lograr el crecimiento del hongo en medios de cultivo habituales, como ocurrió en este reporte. Si la siembra se realiza en medios corrientes para hongos pero sin cicloheximida (que inhibe su crecimiento) y se prolonga el tiempo de observación, aumenta la posibilidad de su recuperación ${ }^{1,2}$. Entre los factores de riesgo para contraer una mucormicosis está el uso de altas dosis de corticoesteroides, hecho presente en nuestro paciente y que se mantiene en los esquemas de quimioterapia actuales.

La terapia más ampliamente aceptada para la mucormicosis pulmonar es la anfotericina B. Es destacable la buena respuesta terapéutica de este caso con dosis totales relativamente bajas (35 $\mathrm{mg} / \mathrm{k}$ ), las dosis estimadas necesarias en adultos son de $50 \mathrm{mg} /$ día y dosis acumulativas de más de dos gramos ${ }^{3}$.

La mucormicosis es una de las infecciones micóticas más agudas y fulminantes. Se caracteriza por un alto grado de necrosis e infartos debido a invasión tisular de las paredes bronquiales, tejido peribronquial y de vasos sanguíneos, provocando trombosis e infarto pulmonar con neumonía progresiva que evoluciona a cavitación y abscedación pulmonar, o la formación de bola fúngica con menor frecuente ${ }^{1}$.

Sus manifestaciones clínicas más comunes pueden ser tos productiva, fiebre, disnea, dolor torácico y hemoptisis. Las causas más frecuentes de muerte son sepsis fúngica, insuficiencia pulmonar progresiva y la hemoptisis masiva ${ }^{4}$. En la serie de Pagano y colaboradores ${ }^{6}$, la hemoptisis fue causa de muerte en 12 de 112 adultos con micosis pulmonar sin ningún signo predictor de complicación fatal. En otra serie de Albeda ${ }^{7}$ se reporta hemoptisis fatal en $26 \%$ de adultos con LLA y aspergilosis invasora. En adultos se promueve la resección quirúrgica precoz del foco infeccioso para prevenir esta seria complicación ${ }^{4}$.

En la literatura médica pediátrica se han descrito sólo unos pocos casos de resección quirúrgica durante la fase aguda de la enfermedad, la mayoría corresponde a niños con resecciones pulmonares efectuadas después de completar la 
quimioterapia o haber recibido transplante de médula ósea bajo condiciones óptimas ${ }^{8}$.

Ante la presencia de un absceso pulmonar, y más aún con derrame pericárdico en un paciente inmunocomprometido, debe sospecharse la presencia de una patología micótica, iniciar tratamiento específico y adoptar una conducta quirúrgica precoz con fines diagnósticos y terapéuticos. La mortalidad de la mucormicosis pulmonar es de $68 \%$ disminuyendo a $11 \%$ si se complementa la terapia específica con tratamiento quirúrgico ${ }^{4}$ globalmente el pronóstico de esta enfermedad está estrechamente relacionado con la reversibilidad de la condición predisponente ${ }^{5}$.

Nuestra limitada experiencia nos lleva a enfatizar un manejo quirúrgico agresivo de esta complicación pulmonar.

\section{Resumen}

Se presenta el caso de un niño de 10 años portador de una leucemia linfoblástica aguda, que encontrándose neutropénico a consecuencia de su tratamiento quimioterápico, presentó un absceso pulmonar. Recibió varios antimicrobianos previos a su drenaje quirúrgico. El estudio histopatológico identificó una mucormicosis siendo tratado con anfotericina $\mathrm{B}$ deoxicolato, con buena respuesta y evolución. La sospecha clínica precoz de la infección micótica en un niño con factores de riesgo, especialmente inmunocomprometidos y diabéticos, y su tratamiento oportuno, son fundamentales para disminuir la alta mortalidad de está enfermedad oportunista. Se enfatiza la importancia del tratamiento combinado médico quirúrgico.

\section{Agradecimientos}

A Aníbal Espinoza G. por su apoyo en la interpretación de las imágenes radiológicas y a Elena Kakarieka por su apoyo en el estudio histopatológico.

\section{Bibliografía}

1.- Wiedermann B L. Zygomicosis. En Feigin RD and Cherry JD editors. Textbook of Pediatric Infectious Diseases. WB Saunders Company, Philadelphia, 1998: 2354-9.

2.- www.med.uchile.cl/otros/dra_ancic/capitulo22.htlm. Thompson L, Oddo D. Micosis oportunistas.

3.- Kontoyiannis D, Wessel V, Bodey G, Rolston K. Zygomycosis in the 1990s in a tertiary-Care Cancer Center. Clin Infect Dis 2000; 30: 851-6.

4.- Tedder M, Spratt J, Anstadt M, Hedge S, Tedder S, Lowe J. Pulmonary mucormycosis: Results of medical and surgical therapy. Ann Thorac Surg 1994; 57: 104450.

5.- Peterson K L, Wang M, Canalis R F, Abemayor E. Rhinocerebral mucormycosis: evolution of the disease and treatment options. Laryngoscope 1997; 107 (7): 855-62.

6.- Pagano L, Ricci P, Tonso A and the Gimema Infection Program. Fatal hemoptysis in pulmonary filamentous mycosis: An underevaluated cause of death in patient with acute leukaemia in haematological complete remission. A retrospective study and review of the literature. Br J Haematol 1995; 89: 500-5.

7.- Albeda S, Talbot G, Gerson S, Miller W, Cassileth P. Pulmonary cavitation and massive hemoptysis in invasive pulmonary aspergillosis. Am Rev Respir Dis1985; 131: 115-20.

8.- Suc A, Bremont F, Rubie H, Guitard J, Voigt J, Recco P. Successful combination of amphotericin therapy and surgical resection for fungal necrotizing pneumonia in a child receiving chemotherapy for leukemia. Pediatr Pulmonol 1997; 23: 386-8.

Correspondencia a:

Carmen Luz Avilés Lohmann

E-mail: claviles@terra.cl 